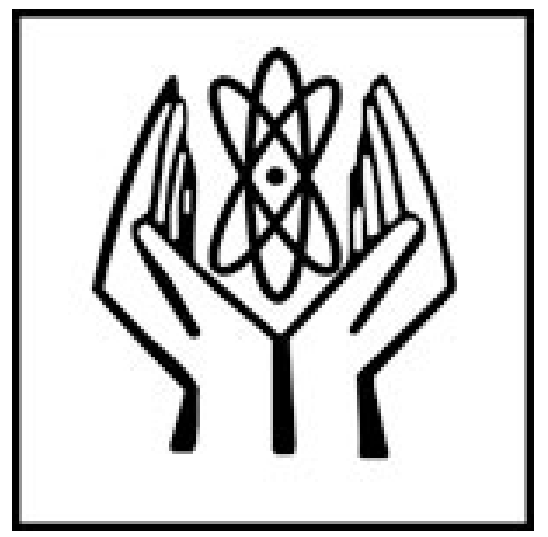

Stable Intrachromosomal Biomarkers of Past Exposure to Densely Ionizing Radiation in Several Chromosomes of Exposed Individuals

Author(s): Catherine R. Mitchell, Tamara V. Azizova, M. Prakash Hande, Ludmilla E. Burak, Josephine M. Tsakok, Valentin F. Khokhryakov, Charles R. Geard, David J. Brenner

Source: Radiation Research, Vol. 162, No. 3 (Sep., 2004), pp. 257-263

Published by: Radiation Research Society

Stable URL: http://www.jstor.org/stable/3581250

Accessed: 24/08/2010 13:17

Your use of the JSTOR archive indicates your acceptance of JSTOR's Terms and Conditions of Use, available at http://www.jstor.org/page/info/about/policies/terms.jsp. JSTOR's Terms and Conditions of Use provides, in part, that unless you have obtained prior permission, you may not download an entire issue of a journal or multiple copies of articles, and you may use content in the JSTOR archive only for your personal, non-commercial use.

Please contact the publisher regarding any further use of this work. Publisher contact information may be obtained at http://www.jstor.org/action/showPublisher?publisherCode=rrs.

Each copy of any part of a JSTOR transmission must contain the same copyright notice that appears on the screen or printed page of such transmission.

JSTOR is a not-for-profit service that helps scholars, researchers, and students discover, use, and build upon a wide range of content in a trusted digital archive. We use information technology and tools to increase productivity and facilitate new forms of scholarship. For more information about JSTOR, please contact support@jstor.org.

Radiation Research Society is collaborating with JSTOR to digitize, preserve and extend access to Radiation Research. 


\title{
Stable Intrachromosomal Biomarkers of Past Exposure to Densely Ionizing Radiation in Several Chromosomes of Exposed Individuals
}

\author{
Catherine R. Mitchell, ${ }^{a, 1}$ Tamara V. Azizova, ${ }^{b}$ M. Prakash Hande, ${ }^{a, 2}$ Ludmilla E. Burak, ${ }^{b}$ Josephine M. Tsakok, ${ }^{a}$ \\ Valentin F. Khokhryakov, ${ }^{b}$ Charles R. Geard ${ }^{a}$ and David J. Brenner ${ }^{a}$ \\ ${ }^{a}$ Center for Radiological Research, Columbia University, 630 West 168th Street, New York, New York 10032; and ${ }^{b}$ Southern Urals Biophysics \\ Institute, Ozyorsk 456780, Russia
}

Mitchell, C. R., Azizova, T. V., Hande, M. P., Burak, L. E., Tsakok, J. M., Khokhryakov, V. F., Geard, C. R. and Brenner, D. J. Stable Intrachromosomal Biomarkers of Past Exposure to Densely Ionizing Radiation in Several Chromosomes of Exposed Individuals. Radiat. Res. 162, 257-263 (2004).

A multicolor banding (mBAND) fluorescence in situ hybridization technique was used to investigate the presence in human populations of a stable biomarker-intrachromosomal chromosome aberrations - of past exposure to high-LET radiation. Peripheral blood lymphocytes were taken from healthy Russian nuclear workers occupationally exposed from 1949 onward to either plutonium, $\gamma$ rays or both. Metaphase spreads were produced and chromosomes 1 and 2 were hybridized with mBAND FISH probes and scored for intrachromosomal aberrations. A large yield of intrachromosomal aberrations was observed in both chromosomes of the individuals exposed to high doses of plutonium, whereas there was no significant increase over the (low) background control rate in the population who were exposed to high doses of $\boldsymbol{\gamma}$ rays. Interchromosome aberration yields were similar in both the high plutonium and the high $\gamma$-ray groups. These results for chromosome 1 and 2 confirm and extend data published previously for chromosome 5. Intrachromosomal aberrations thus represent a potential biomarker for past exposure to high-LET radiations such as $\alpha$ particles and neutrons and could possibly be used as a biodosimeter to estimate both the dose and type of radiation exposure in previously exposed populations. 2004 by Radiation Research Society

\section{INTRODUCTION}

There is considerable interest in studying the effects of densely ionizing (high-LET) radiations such as $\alpha$ particles (e.g. from radon or plutonium exposure) or neutrons (e.g. flight personnel or occupational neutron exposure). Cur-

\footnotetext{
' Address for correspondence: Center for Radiological Research, Columbia University, 630 West 168th St., New York, NY 10032; e-mail: cm2073@columbia.edu.

${ }^{2}$ Current address: Department of Physiology, Faculty of Medicine, National University of Singapore, 2 Medical Drive, Singapore 117597, Singapore.
}

rently, however, it is difficult to quantify the past exposure of populations to such high-LET radiations. The existence of a stable biomarker in the genome that is dose-dependent and radiation quality-specific would be a valuable asset to radiation epidemiology. The possible utility of cytogenetic markers for this purpose has been discussed for some time (1-6), but only recently have techniques become available that allow more detailed investigations of such chromosome aberrations.

Specifically, an excess of intrachromosomal aberrations (aberrations occurring within a single chromosome) has been suggested as a biomarker of past exposure to highLET radiations (1). The rationale is that densely ionizing radiations produce highly localized DNA damage at the chromosomal level. This is in contrast to almost all other mutagens, such as chemicals, $\mathrm{X}$ rays or general aging processes, all of which produce a far more homogeneous spatial distribution of DNA damage. Thus densely ionizing radiations preferentially produce multiple DNA breaks within single chromosomes, which are themselves confined within localized domains (7). In that exchange-type chromosome aberrations are produced primarily by the misrepair of pairs of DNA breaks, there will be a preference for densely ionizing radiations to produce intrachromosomal aberrations. By contrast, because chemical mutagens, $\mathrm{X}$ rays and endogenous processes generally produce chromosome breaks that are distributed relatively uniformly across many or all chromosomes, there is a preference for them to produce interchromosomal aberrations such as translocations.

Examples of intrachromosomal aberrations are pericentric inversions (misrepair of two breaks on different arms of one chromosome), paracentric inversions (misrepair of two breaks on a single chromosome arm), and interstitial deletions. All of these aberrations are potentially stable (heritable). It may be possible, therefore, to examine intrachromosome aberration yields in lymphocytes from a previously exposed individual and to use the results to estimate whether, and to what high-LET radiation dose, the individual had been exposed.

In this study, a cohort of radiation workers with previous 
TABLE 1

Details of the Three Exposed Groups Studied

\begin{tabular}{lccc}
\hline & $\begin{array}{c}\text { Highly exposed } \\
\text { plutonium workers }(n=11)\end{array}$ & $\begin{array}{c}\text { Reactor workers (zero } \\
\text { plutonium intake) }(n=11)\end{array}$ & $\begin{array}{c}\text { Moderately exposed } \\
\text { plutonium workers }(n=4)\end{array}$ \\
\hline Mean start/end dates of occupational exposure & 1951 (start)/1971 (end) & 1949 (start)/1977 (end) & 1960 (start)/1989 (end) \\
Mean age at time of sampling (range) & $75(68-82)$ & $74(67-82)$ & $66(62-77)$ \\
Mean plutonium dose to bone marrow (Gy) (range) & $1.1(0.4-2.1)$ & 0 & $0.19(0.11-0.33)$ \\
Mean $\gamma$-ray dose to bone marrow (Gy) (range) & $1.5(0-3.1)$ & $2.3(1.5-3.8)$ & $0.19(0.07-0.31)$ \\
\hline
\end{tabular}

"The mean age (and age range) of the controls was 60 (43-77).

exposure to high- and/or low-LET radiation, together with controls, has been examined for the presence of intrachromosomal aberrations in their peripheral blood lymphocytes (PBLs). Visualizing intrachromosomal aberrations is difficult using established cytogenetic techniques: Single or two/three-color whole chromosome painting techniques such as FISH do not allow the observation of aberrations present within one chromosome. However, the recent development of multicolor banding (mBAND) FISH techniques (8) allows single chromosomes to be "painted" with a series of colored bands along the axis. Loss or rearrangement of the bands indicates an intrachromosomal aberration $(8,9)$.

The cohort of radiation workers is from the Mayak Production Association near Ozyorsk, Russia (10). The Mayak Production Association began operations in 1948 as a nuclear weapons facility, and a substantial number of workers have been occupationally exposed to plutonium, $\gamma$ rays or both. These workers therefore offer a unique opportunity to study the effects of exposure to radiation of different qualities, due to the reliable dosimetric and medical information available for each individual, and particularly because of the very low mobility rates of the Mayak workers (10).

We have previously published results from this cohort using mBAND to examine intrachromosomal aberrations in chromosome 5 and multi-fluor FISH (mFISH) (11) to examine interchromosomal aberrations (6). A significantly larger number of intrachromosomal aberrations (inversions and interstitial deletions) were observed in the group exposed to high doses of plutonium, compared with the group exposed only to high doses of $\gamma$ rays. By contrast, the yield of interchromosomal aberrations was similar for the two groups. Based on these results and the underlying theoretical background, the yield of intrachromosomal aberrations was proposed as a long-lived biomarker of past exposure to high-LET radiation. The present study investigates both the presence and magnitude of corresponding intrachromosomal biomarkers in chromosomes 1 and 2 .

\section{MATERIALS AND METHODS}

\section{Population Studied}

Peripheral blood lymphocytes (PBLs) were examined from 26 healthy radiation workers from the Mayak Production Association who were occupationally exposed to plutonium, $\gamma$ rays or both from 1949 onward (10). These were the same individuals that were examined previously for aberrations in chromosome 5 (6). Details of the groups studied are shown in Table 1. In brief, 11 of these workers were exposed to high doses of $\alpha$ particles ( $\geq 0.4$ Gy bone marrow dose) as a consequence of plutonium inhalation, 11 were exposed to high doses of $\gamma$ rays $(\geq 1.5$ Gy bone marrow dose) but no plutonium, and four were exposed to moderate doses $(<0.4$ Gy bone marrow dose $)$ of both plutonium and $\gamma$ rays. Five control individuals who were unexposed workers at the Mayak plant were also examined. Details of the dosimetry are summarized elsewhere $(12,13)$. In brief, plutonium dosimetry was based on urine sample measurements and application of biokinetic models, and $\gamma$-ray exposure was estimated from film badge data.

The study was approved by the Columbia University Medical Center Institutional Review Board and the Southern Urals Biophysics Institute Institutional Review Board. Informed consent was obtained from all blood donors.

\section{Chromosome Preparations}

Blood samples were taken at the Southern Urals Biophysics Institute (SUBI), and metaphase spreads of PBLs were produced using the following protocol (14): $10 \mathrm{ml}$ of PB-MAX karyotyping medium was placed in a $25-\mathrm{cm}^{2}$ tissue culture flask; $0.75 \mathrm{ml}$ of blood was then added. The flask was then incubated at $37^{\circ} \mathrm{C}$ in $95 \%$ air $/ 5 \% \mathrm{CO}_{2}$ for 48 to $68 \mathrm{~h}$. Then $0.01 \mu \mathrm{g} / \mathrm{ml}$ Colcemid was added and the flask was further incubated for 1-2 h. The flask contents were then centrifuged at $800 \mathrm{rpm}$ for $8 \mathrm{~min}$. The supernatant was removed and the pellet was resuspended in $7 \mathrm{ml}$ of $0.075 \mathrm{M} \mathrm{KCl}$ and placed in a $37^{\circ} \mathrm{C}$ water bath for $15 \mathrm{~min}$. The preparation was then centrifuged at $800 \mathrm{rpm}$ for $8 \mathrm{~min}$ and the supernatant removed. The pellet was then resuspended in $7 \mathrm{ml}$ of ice-cold fixative (1:3 glacial acetic acid:methanol). This was then centrifuged at $1000 \mathrm{rpm}$ for $8 \mathrm{~min}$, the supernatant was replaced with $7 \mathrm{ml}$ fresh fixative and the sample was incubated for $10 \mathrm{~min}$ at room temperature. This step was repeated twice, with the second incubation carried out at $4^{\circ} \mathrm{C}$. The cell suspension was finally centrifuged at $1200 \mathrm{rpm}$ for $7 \mathrm{~min}$ and the pellet was resuspended in $1 \mathrm{ml}$ fixative. Slides were prepared by placing three to six drops of cell suspension on a slide. Slides were allowed to dry and were then examined under the microscope to check for the presence of metaphases. The slides were then packed and shipped from Russia to the U.S., where they were stored at $-20^{\circ} \mathrm{C}$ prior to hybridization.

\section{Hybridization of Chromosomes with mBAND Probes}

Prior to hybridization, protein digestion was carried out on the slides to remove any remaining cytoplasmic cellular proteins that may have impaired hybridization. A solution containing $1 \mathrm{ml}$ of $1 \mathrm{~N} \mathrm{HCl}, 99 \mathrm{ml}$ of distilled water, and $500 \mu$ l of pepsin was preheated to $37^{\circ} \mathrm{C}$. The slides were immersed in this solution for $1 \mathrm{~min}$ and then briefly in PBS. Then $100 \mu \mathrm{l}$ of a post-fixation solution ( $1 \%$ formaldehyde and $50 \mathrm{mM} \mathrm{MgCl}$ in PBS) was applied to each slide. The slides were then incubated at room temperature for $10 \mathrm{~min}$ and washed in PBS for $1 \mathrm{~min}$.

Slides were immersed in $0.1 \times$ SSC buffer for $1 \mathrm{~min}$ before being transferred to $2 \times \mathrm{SSC}$ preheated to $70^{\circ} \mathrm{C}$ for $30 \mathrm{~min}$ and then allowed to cool to room temperature. The slides were then transferred to $0.1 \times$ SCC at room temperature for $1 \mathrm{~min}$ and then denatured by immersion in $0.07 \mathrm{~N} \mathrm{NaOH}$ solution for $1 \mathrm{~min}$ before being transferred to $0.1 \times \mathrm{SSC}$ at 
$4^{\circ} \mathrm{C}$ for $1 \mathrm{~min}$. Slides were again transferred to $2 \times \mathrm{SSC}$ at $4^{\circ} \mathrm{C}$ before being dehydrated by immersion for $1 \mathrm{~min}$ in each of $30 \%, 50 \%, 70 \%$, $90 \%$ and $100 \%$ ethanol. Slides were then allowed to air-dry.

mBAND probes (MetaSystems) were prepared as follows: The required amount of probe (XCyte1 and XCyte2) was pipetted into Eppendorf tubes. Probes were denatured by incubation at $75^{\circ} \mathrm{C}$ in a water bath for $5 \mathrm{~min}$. The tubes were transferred to ice briefly before being incubated at $37^{\circ} \mathrm{C}$ for $30 \mathrm{~min}$. Then $12 \mu \mathrm{l}$ of the probe for chromosome 1 (XCyte1) was applied to one half of the slide and a cover slip was applied. The same was done for chromosome 2 probe (XCyte2) on the other half of the slide. The edges of the cover slip were then sealed using rubber cement, and the slides were placed in a humidified chamber in a $37^{\circ} \mathrm{C}$ incubator for 3 days.

After incubation, the rubber cement was carefully removed and the cover slips were discarded. The slides were washed in $1 \times \mathrm{SSC}$ at $75^{\circ} \mathrm{C}$ for $5 \mathrm{~min}$ and then immersed in $4 \times$ SSC containing $0.05 \%$ Tween (SSCT) at room temperature. Then $50 \mu \mathrm{l}$ of blocking reagent (provided in the XCyte kit) was applied to the slide. Slides were then incubated at $37^{\circ} \mathrm{C}$ for $10 \mathrm{~min}$. Slides were briefly immersed in $4 \times$ SSCT before the application of $50 \mu \mathrm{l}$ of blocking reagent containing $1 \mu$ l detection $1+3$ reagent (provided in the XCyte kit) and further incubated for $20 \mathrm{~min}$ at $37^{\circ} \mathrm{C}$. Slides were washed twice for 3 min with $4 \times$ SSCT. Then $50 \mu$ lof blocking reagent containing $1 \mu$ ldetection 2 reagent (provided in the XCyte kit) was applied to the slides before incubation at $37^{\circ} \mathrm{C}$ for $15 \mathrm{~min}$. Slides were washed twice for $3 \mathrm{~min}$ with $4 \times$ SSCT. Application of $50 \mu \mathrm{l}$ of blocking reagent containing $1 \mu$ detection $1+3$ reagent was repeated and the slides were incubated for $20 \mathrm{~min}$ at $37^{\circ} \mathrm{C}$. Slides were washed twice for 3 min with $4 \times$ SSCT. Slides were finally washed for $1 \mathrm{~min}$ in PBS before being allowed to air-dry. Then $20 \mu$ l of DAPI/antifade solution (provided in the XCyte kit) was applied to each slide and a cover slip was applied, and the chromosomes were then captured and analyzed by microscopy.

\section{Capture and Analysis of mBAND Hybridized Chromosomes}

Microscopic analysis was performed using an Axioplan II imaging microscope (Carl Zeiss, Germany) with an HBO-103 mercury lamp and filter sets for FITC (fluorescein isothiocyanate), Cy3.5, Texas Red, Cy5 and AQUA. Images were captured, processed and analyzed using Isis mBAND/mFISH imaging software (MetaSystems). Although only two chromosomes were colored using mBAND, whole metaphases were also captured to observe any interchromosomal translocations. Raw images were "cleaned" manually (i.e., chromosomes were separated from one another and a background correction of color was made). The mBAND technique for detecting intrachromosomal aberrations $(8,15)$ is based on region-specific chromosome paints (RSCP) labeled using unique fluorochrome combinations, combined with quantitative color ratio analysis. Five different fluorochromes are used, FITC, Spectrum Orange, Texas Red, DEAC (diethylamino-coumarin), and biotin (detected with Streptavidin-Cy 5).

The partial overlap between adjacent RSCPs results in a "merged color" continuously changing fluorescence pattern along the chromosome axis, quantified as a continuous change of color ratios. "Pseudo colors" are assigned to chromosome sections with similar color ratios, resulting in a reproducible color banding pattern that is virtually independent of chromosome condensation.

Observation of the banding pattern in the pseudo-color images allows the visualization of intrachromosomal aberrations. Reversal of the order of the colors may signify an intrachromosomal inversion, and missing bands may constitute an interstitial deletion. The minimum detectable size of the intrachromosomal rearrangements is determined by the width of the bands and is around $6 \mathrm{Mb}$. Manual observation was used to score the frequency of these intrachromosomal aberrations. A total of 120-150 metaphases were analyzed by each scorer per individual.

\section{Measurement Reproducibility}

As discussed above, the intrachromosomal aberrations are scored manually based on the pseudocolor images augmented, where necessary, by examination of images from individual fluorochromes. It is important, therefore, to assess the degree of observer dependence inherent in this process. To address this issue, all the slides were scored independently by two different observers. The results reported previously for chromosome $5(6)$ were also rescored by two further observers.

\section{RESULTS}

Figure 1 shows an example of a pericentric inversion found in chromosome 2 from one of the high plutoniumexposed workers. Tables 2 and 3 show the aberrations observed within each group using mBAND analysis. These tables separately show the results of each of the two scorers (CRM and JMT). For each of the 56 categories in these tables (seven aberration types, four worker groups, two chromosomes), Fisher's exact test was used to investigate whether there were systematic differences between the results of the two observers. No statistically significant differences were seen.

Table 4 and Fig. 2 show the pooled data for stable intrachromosome aberrations in chromosomes 1 and 2, as well as the corresponding data for chromosome 5 [which includes the results reported earlier (6), augmented with repeat scoring by CRM and JMT]. Figure 3 shows the corresponding results for stable interchromosomal aberrations, taken from ref. (6).

In absolute terms, the measured yield of intrachromosomal aberrations in the high-plutonium group was very high $-5.3 \%$ of the cells examined contained such aberrations in one of the three chromosomes examined. Extrapolated to the whole genome, this implies that about $24 \pm$ $5 \%$ of the cells of the individuals in the high-plutonium group contain large intrachromosomal aberrations.

It is clear from Fig. 2 that the frequency of intrachromosomal aberrations (paracentric, pericentric and complex inversions and interstitial deletions) was significantly higher in the high plutonium group compared with the high $\gamma$ ray group. By contrast, the yield of interchromosomal aberrations (Fig. 3) was similar in both groups.

The yield of intrachromosomal aberrations in the high $\gamma$ ray group was not significantly different from the control group. Similarly, the yield of intrachromosomal aberrations in the medium plutonium/medium $\gamma$-ray group was not significantly different from controls, though the small number of individuals (four) in this group makes it difficult to draw firm conclusions.

\section{DISCUSSION}

In each of the three chromosomes that we examined (1, 2 and 5), there is a highly significant excess of intrachromosomal aberrations in the individuals who were highly exposed to plutonium compared with the highly exposed reactor workers who were not exposed to plutonium. This 


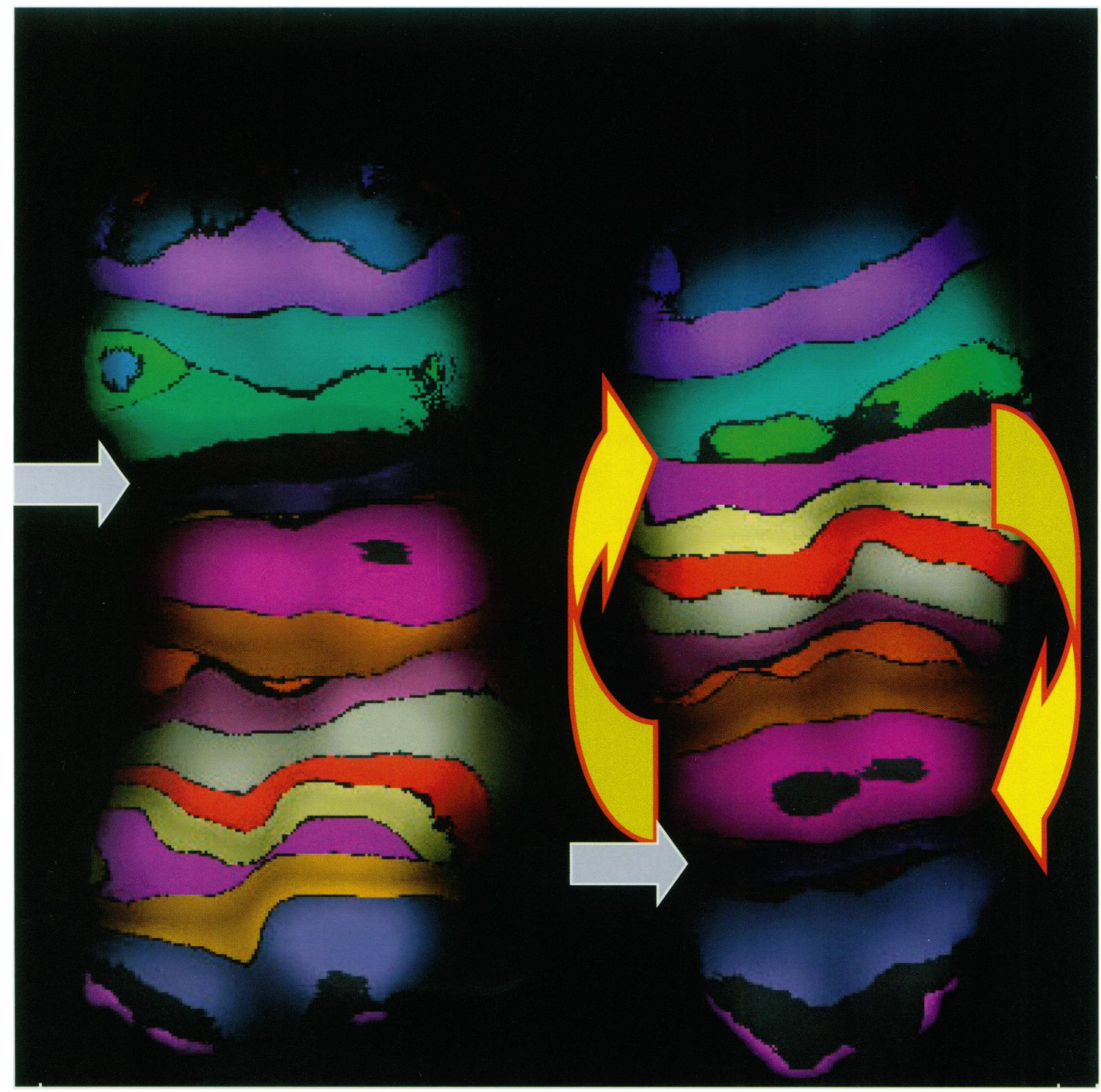

FIG. 1. Intrachromosomal aberration detected in chromosome 2 of a peripheral blood lymphocyte (PBL) of a highly exposed plutonium worker. The left chromosome is normal and the right shows the aberration. Gray arrows denote the centromeres. Yellow arrows indicate the region of the chromosome that was inverted, as indicated by the reversal in the sequence of band colors. This is an example of an interarm intrachromosomal aberration (pericentric inversion) with an interstitial deletion (yellow band is present in left chromosome and is absent in right).

TABLE 2

Aberrations Observed in Chromosome 1 Using mBAND

\begin{tabular}{|c|c|c|c|c|c|c|c|c|c|}
\hline \multirow[b]{2}{*}{ Group $^{a}$} & \multirow[b]{2}{*}{$\begin{array}{l}\text { Individuals } \\
\text { analyzed }\end{array}$} & \multirow[b]{2}{*}{$\begin{array}{c}\text { Cells } \\
\text { analyzed }\end{array}$} & \multicolumn{4}{|c|}{ Intrachromosomal aberrations } & \multicolumn{3}{|c|}{ Other detectable aberrations } \\
\hline & & & $\begin{array}{l}\text { Paracentric } \\
\text { inversions }\end{array}$ & $\begin{array}{l}\text { Pericentric } \\
\text { inversions }\end{array}$ & $\begin{array}{l}\text { Complex } \\
\text { inversions }\end{array}$ & $\begin{array}{l}\text { Interstitial } \\
\text { deletions }\end{array}$ & $\begin{array}{l}\text { Terminal } \\
\text { deletions }\end{array}$ & Insertions & Translocations \\
\hline \multirow[t]{2}{*}{ High plutonium } & 8 & 1012 & 2 & 1 & 2 & 13 & 6 & 0 & 9 \\
\hline & 8 & 1093 & 3 & 1 & 1 & 11 & 2 & 2 & 6 \\
\hline \multirow[t]{2}{*}{ High $\gamma$ rays } & 10 & 1281 & 0 & 2 & 0 & 0 & 1 & 0 & 11 \\
\hline & 10 & 1328 & 0 & 1 & 0 & 0 & 0 & 0 & 6 \\
\hline \multirow{2}{*}{$\begin{array}{l}\text { Moderate } \\
\text { plutonium and } \\
\text { moderate } \gamma \text { rays }\end{array}$} & 4 & 497 & 0 & 0 & 0 & 0 & 0 & 0 & 3 \\
\hline & 4 & 500 & 0 & 0 & 0 & 1 & 0 & 0 & 6 \\
\hline \multirow[t]{2}{*}{ Controls } & 4 & 561 & 0 & 0 & 0 & 0 & 0 & 0 & 1 \\
\hline & 4 & 574 & 0 & 0 & 0 & 1 & 0 & 0 & 2 \\
\hline
\end{tabular}

${ }^{a}$ High plutonium; $\geq 0.4$ Gy bone marrow dose; high $\gamma$ rays: $\geq 1.5$ Gy bone marrow dose and zero plutonium; moderate plutonium and moderate $\gamma$ rays: $<0.4$ Gy plutonium dose, $<0.4$ Gy $\gamma$ rays. 
TABLE 3

Aberrations Observed in Chromosome 2 Using mBAND

\begin{tabular}{|c|c|c|c|c|c|c|c|c|c|}
\hline \multirow[b]{2}{*}{ Group $^{a}$} & \multirow[b]{2}{*}{$\begin{array}{c}\text { Individuals } \\
\text { analyzed }\end{array}$} & \multirow[b]{2}{*}{$\begin{array}{c}\text { Cells } \\
\text { analyzed }\end{array}$} & \multicolumn{4}{|c|}{ Intrachromosomal aberrations } & \multicolumn{3}{|c|}{ Other detectable aberrations } \\
\hline & & & $\begin{array}{l}\text { Paracentric } \\
\text { inversions }\end{array}$ & $\begin{array}{l}\text { Pericentric } \\
\text { inversions }\end{array}$ & $\begin{array}{c}\text { Complex } \\
\text { inversions }\end{array}$ & $\begin{array}{c}\text { Interstitial } \\
\text { deletions }\end{array}$ & $\begin{array}{l}\text { Terminal } \\
\text { deletions }\end{array}$ & Insertions & Translocations \\
\hline \multirow[t]{2}{*}{ High plutonium } & 9 & 1203 & 1 & 2 & 1 & 13 & 6 & 0 & 10 \\
\hline & 9 & 1229 & 0 & 3 & 1 & 7 & 2 & 0 & 8 \\
\hline \multirow[t]{2}{*}{ High $\gamma$ rays } & 10 & 1404 & 0 & 0 & 0 & 0 & 4 & 0 & 10 \\
\hline & 10 & 1413 & 1 & 3 & 0 & 1 & 3 & 1 & 8 \\
\hline \multirow{2}{*}{$\begin{array}{l}\text { Moderate } \\
\text { plutonium and } \\
\text { moderate } \gamma \text { rays }\end{array}$} & 3 & 412 & 0 & 0 & 0 & 0 & 1 & 0 & 3 \\
\hline & 3 & 436 & 0 & 0 & 0 & 2 & 1 & 0 & 2 \\
\hline \multirow[t]{2}{*}{ Controls } & 5 & 681 & 0 & 0 & 0 & 2 & 0 & 0 & 4 \\
\hline & 5 & 696 & 0 & 0 & 0 & 1 & 0 & 0 & 4 \\
\hline
\end{tabular}

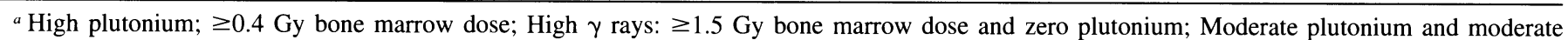
$\gamma$ rays: $<0.4$ Gy plutonium, $<0.4$ Gy $\gamma$ rays.

was not the case for the measured interchromosomal aberrations. Thus these measurements reveal an unequivocal biomarker of densely ionizing radiation exposure in a human population that was exposed many years ago.

Despite their healthy and long-lived status, the highly exposed plutonium workers who were examined still maintain a large burden of stable intrachromosomal aberrations, many years after occupational exposure. Overall, we estimate that about a quarter of all the cells in these individuals contain detectable $(\geq 6 \mathrm{Mb}$ ) intrachromosomal aberrations. Such large numbers of intrachromosomal aberrations have been predicted on theoretical grounds (16) and have been observed in vitro for unstable (non-transmissible) aberrations (5), but until recently, practical procedures were not available to rapidly and reliably detect stable intrachromosomal aberrations.

The results depicted in Fig. 2 for chromosomes 1 and 2 confirm the previously published intrachromosomal data for chromosome 5 (6) in terms of a clear biomarker of exposure to high-LET radiation. However, the intrachromosomal aberration frequencies observed in the present study for chromosomes 1 and 2 are somewhat lower than that observed for chromosome 5 . The differences in intrachromosomal aberration yields between chromosomes 1 and 2 and chromosome 5 are barely statistically significant (Fisher's exact test), but the differences in intrachromosomal yield per unit DNA content of each chromosome are significant, with chromosome 5 having a larger yield per unit DNA content $\left(12.7 \pm 2.1 / 10^{5} \mathrm{Mb}\right)$ than either chromosome $1\left(5.6 \pm 1.4 / 10^{5} \mathrm{Mb}\right)$ or chromosome $2\left(4.5 \pm 2.1 / 10^{5} \mathrm{Mb}\right)$. This difference, though not large, is surprising since the yield of intrachromosomal aberrations would be expected to be approximately proportional to the DNA content of the chromosome, analogous to the dependence on DNA content observed for interchromosomal aberrations $(17,18)$. A large study investigating chromosomal translocations in humans identified chromosomal DNA content as the major determinant of interchromosomal frequency (19), having much more influence than factors such as gene density or nuclear position. Similar results have also been reported using Giemsa banding in A-bomb survivors (20), but our mBAND results to date for individuals irradiated many

TABLE 4

Observer-Averaged Comparison of Total Intrachromosomal Aberration Yields and Frequencies Observed in Chromosomes 1, 2 and 5 (Mean \pm 1 SD)

\begin{tabular}{|c|c|c|c|}
\hline \multirow[b]{2}{*}{ Group $^{a}$} & \multicolumn{3}{|c|}{$\begin{array}{l}\text { Intrachromosomal aberrations/metaphase cell (averaged from two independent } \\
\text { scorers); Aberration frequencies per cell examined (mean } \pm 1 \mathrm{SD} \text { ) }\end{array}$} \\
\hline & Chromosome 1 & Chromosome 2 & Chromosome $5^{b}$ \\
\hline \multirow[t]{2}{*}{ High plutonium exposure } & $17 / 1052$ & $14 / 1216$ & $37.7 / 1474$ \\
\hline & $1.62 \pm 0.39 \%$ & $1.15 \pm 0.30 \%$ & $2.55 \pm 0.43 \%$ \\
\hline \multirow[t]{2}{*}{ High $\gamma$-ray exposure } & $1.5 / 1304$ & $2.5 / 1408$ & $4 / 1447$ \\
\hline & $0.11 \pm 0.09 \%$ & $0.18 \pm 0.11 \%$ & $0.28 \pm 0.14 \%$ \\
\hline \multirow[t]{2}{*}{ Moderate plutonium and moderate $\gamma$-ray exposure } & $0.5 / 499$ & $1 / 424$ & $1.7 / 461$ \\
\hline & $0.10 \pm 0.10 \%$ & $0.24 \pm 0.24 \%$ & $0.36 \pm 0.28 \%$ \\
\hline \multirow[t]{2}{*}{ Controls } & $0.5 / 568$ & $1.5 / 688$ & $1 / 611$ \\
\hline & $0.09 \pm 0.09 \%$ & $0.22 \pm 0.18 \%$ & $0.16 \pm 0.16 \%$ \\
\hline
\end{tabular}

${ }^{a}$ High plutonium; $\geq 0.4$ Gy bone marrow dose; High $\gamma$ rays: $\geq 1.5$ Gy bone marrow dose and zero plutonium; moderate plutonium and moderate $\gamma$ rays: $<0.4$ Gy plutonium; $<0.4$ Gy $\gamma$ rays. (6)

${ }^{b}$ Averaged results from three independent scorers (CRM, JMT and MPH). Results for chromosome 5, scored by MPH, previously reported in ref. 


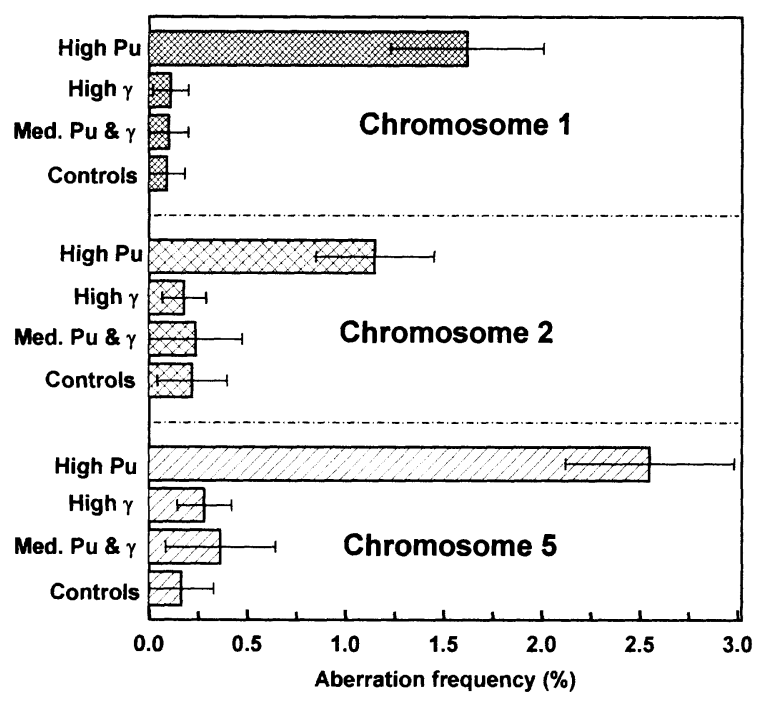

FIG. 2. Measured yields of stable intrachromosomal aberrations in PBLs of individuals after high-dose exposure to plutonium ( $\mathrm{Pu}, \geq 0.4 \mathrm{~Gy}$ bone marrow dose), high-dose exposure to $\gamma$ rays ( $\geq 1.5$ Gy bone marrow dose and zero plutonium), medium exposure to both plutonium and $\gamma$ rays ( $<0.4$ Gy plutonium, $<0.4$ Gy $\gamma$ rays), and unexposed controls. The mean numbers of intrachromosomal aberrations are shown.

years ago with high-LET radiation indicate that factors other than simply DNA content may also be significant; the complex interactions between track structure and chromatin organization, over several levels, have been noted earlier (21).

Based on measurements with the control population, the background frequency of intrachromosomal aberrations in the three chromosomes studied is very low $(0.16 \pm 0.09 \%)$, much lower than the interchromosomal aberration background $(0.7 \pm 0.3 \%)$. Background aberrations are unlikely to be the result of densely ionizing radiation, and other mutagens and endogenous processes would indeed be expected primarily to produce interchromosomal aberrations (1). The background aberration rate is an important issue for dose reconstruction at low doses, in that it determines the minimum radiation dose that can be reconstructed from measured aberration data.

In conclusion, we have confirmed by examining chromosomes 1 and 2 the previous conclusion for chromosome 5 that intrachromosomal aberrations represent a sensitive, long-lived, quantitative, low-background biomarker of exposure in human populations exposed to densely ionizing radiation many years earlier. Even many years after occupational exposure, about a quarter of the blood cells of the healthy plutonium workers contain large $(\geq 6 \mathrm{Mb})$ intrachromosomal rearrangements; the various control groups contained very few such intrachromosomal aberrations. Quantification of this large-scale chromosomal damage in human populations exposed many years earlier should lead to new insights into the mechanisms of cytogenetic damage as well as significantly enhancing epidemiological studies.

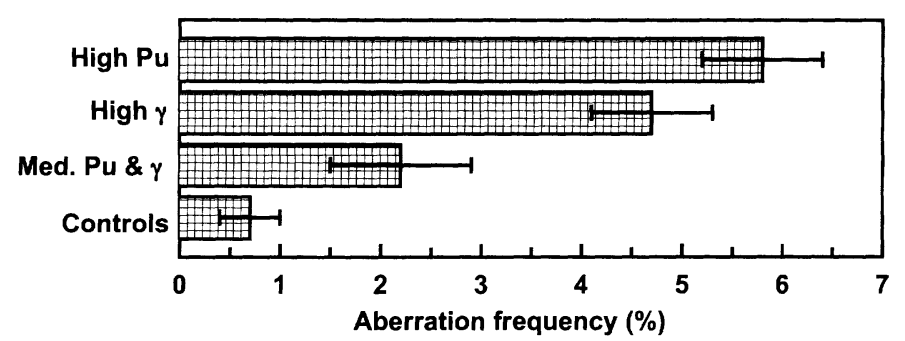

FIG. 3. Measured yields of stable interchromosomal aberrations, measured with mFISH, in PBLs of individuals after exposure to high levels of plutonium or $\gamma$ rays, moderate exposure to both plutonium and $\gamma$ rays, and unexposed controls. Data are from ref. (6). The mean numbers of interchromosomal aberrations are shown.

\section{ACKNOWLEDGMENTS}

This work was supported by grant DE-FC03-01EH01002 from the U.S. Department of Energy. We are grateful for helpful advice from Drs. Evgeny Vasilenko, Rainer Sachs, Nadia Okladnikova, Ruth Neta and Barrett Fountos. Most especially, we acknowledge the friendly cooperation of the Mayak workers in Ozyorsk.

Received: January 26, 2004; accepted: May 14, 2004

\section{REFERENCES}

1. D. J. Brenner and R. K. Sachs, Chromosomal "fingerprints" of prior exposure to densely ionizing radiation. Radiat. Res. 140, 134-142 (1994).

2. W. Deng, D. P. Morrison, K. L. Gale and J. N. Lucas, A comparative study on potential cytogenetic fingerprints for radiation LET in human lymphocytes. Int. J. Radiat. Biol. 76, 1589-1598 (2000).

3. E. Schmid, H. Braselmann and M. Bauchinger, Does the limiting $F$ value at very low doses depend systematically on linear energy transfer? Radiat. Res. 152, 563-566 (1999).

4. R. M. Anderson, S. J. Marsden, S. J. Paice, A. E. Bristow, M. A. Kadhim, C. S. Griffin and D. T. Goodhead, Transmissible and nontransmissible complex chromosome aberrations characterized by three-color and mFISH define a biomarker of exposure to high-LET alpha particles. Radiat. Res. 159, 40-48 (2003).

5. M. Bauchinger and E. Schmid, LET dependence of yield ratios of radiation-induced intra- and interchromosomal aberrations in human lymphocytes. Int. J. Radiat. Biol. 74, 17-25 (1998).

6. M. P. Hande, T. V. Azizova, C. R. Geard, L. E. Burak, C. R. Mitchell, V. F. Khokhryakov, E. K. Vasilenko and D. J. Brenner, Past exposure to densely ionizing radiation leaves a unique permanent signature in the genome. Am. J. Hum. Genet. 72, 1162-1170 (2003).

7. T. Cremer and C. Cremer, Chromosome territories, nuclear architecture and gene regulation in mammalian cells. Nat. Rev. Genet. 2 , 292-301 (2001).

8. I. Chudoba, A. Plesch, T. Lorch, J. Lemke, U. Claussen and G. Senger, High resolution multicolor-banding: A new technique for refined FISH analysis of human chromosomes. Cytogenet. Cell Genet. 84, 156-160 (1999).

9. C. Johannes, I. Chudoba and G. Obe, Analysis of X-ray-induced aberrations in human chromosome 5 using high-resolution multicolour banding FISH (mBAND). Chromosome Res. 7, 625-633 (1999).

10. L. R. Anspaugh, M. O. Degteva and E. K. Vasilenko, Mayak Production Association: Introduction. Radiat. Environ. Biophys. 41, 1922 (2002).

11. M. R. Speicher, S. G. Ballard and D. C. Ward, Karyotyping human chromosomes by combinatorial multi-fluor FISH. Nat. Genet. 12, 368-375 (1996).

12. S. A. Romanov, E. K. Vasilenko, V. F. Khokhryakov and P. Jacob, 
Studies on the Mayak nuclear workers: Dosimetry. Radiat. Environ. Biophys. 41, 23-28 (2002).

13. V. F. Khokhryakov, K. G. Suslova, V. V. Vostrotin, S. A. Romanov, Z. S. Menshikh, T. I. Kudryavtseva, R. E. Filipy, S. C. Miller and M. P. Krahenbuhl, The development of the plutonium lung clearance model for exposure estimation of the Mayak Production Association, nuclear plant workers. Health Phys. 82, 425-431 (2002).

14. L. E. Burak, Y. Kodama, M. Nakano, K. Ohtaki, M. Itoh, N. D. Okladnikova, E. K. Vasilenko, J. B. Cologne and N. Nakamura, FISH examination of lymphocytes from Mayak workers for assessment of translocation induction rate under chronic radiation exposures. Int. J. Radiat. Biol. 77, 901-908 (2001).

15. J. J. Boei, S. Vermeulen, J. Moser, L. H. Mullenders and A. T. Natarajan, Intrachanges as part of complex chromosome-type exchange aberrations. Mutat. Res. 504, 47-55 (2002).

16. R. K. Sachs, D. J. Brenner, A. M. Chen, P. Hahnfeldt and L. R. Hlatky, Intra-arm and interarm chromosome intrachanges: Tools for probing the geometry and dynamics of chromatin. Radiat. Res. 148, 330-340 (1997).
17. M. N. Cornforth, K. M. Greulich-Bode, B. D. Loucas, J. Arsuaga, M. Vazquez, R. K. Sachs, M. Bruckner, M. Molls, P. Hahnfeldt and D. J. Brenner, Chromosomes are predominantly located randomly with respect to each other in interphase human cells. J. Cell Biol. 159, 237-244 (2002).

18. K. L. Johnson, D. J. Brenner, J. Nath, J. D. Tucker and C. R. Geard, Radiation-induced breakpoint misrejoining in human chromosomes: Random or non-random? Int. J. Radiat. Biol. 75, 131-141 (1999).

19. W. A. Bickmore and P. Teague, Influences of chromosome size, gene density and nuclear position on the frequency of constitutional translocations in the human population. Chromosome Res. 10, 707-715 (2002).

20. R. K. Sachs, A. Awa, Y. Kodama, M. Nakano, K. Ohtaki and J. N. Lucas, Ratios of radiation-produced chromosome aberrations as indicators of large-scale DNA geometry during interphase. Radiat. Res. 133, 345-350 (1993).

21. I. Radulescu, K. Elmroth and B. Stenerlow, Chromatin organization contributes to non-randomly distributed double-strand breaks after exposure to high-LET radiation. Radiat. Res. 161, 1-8 (2004). 